\title{
Research on Initial Stiffness of Top-and-Seat Angle Semirigid Connections
}

\author{
Liu Wei ${ }^{1,2, *}$ and Shu Ganping ${ }^{2}$ \\ ${ }^{I}$ Department of Architectural Engineering, Hefei University, Hefei 230022, China; ${ }^{2}$ School of Civil Engineering, South- \\ east University, Nanjing 210096, China
}

\begin{abstract}
Based on the mechanical characteristics, deformation characteristics of top-and-seat angle semirigid connections, the initial stiffness of the connections were studied. The initial stiffness were derived theoretically with component method. Analytical formulas and fitted formulas were obtained, and these formulas were analysed comparatively with test data and FEA results. The results of the research indicated that the initial stiffness of top-and-seat angle semirigid connections were expressed accurately by the fitted formula in the paper, and fit accurately with test data and FEA results. The results provided good condition for practical calculation method of such semirigid connections.
\end{abstract}

Keywords: Initial stiffness, semi-rigid connections, top-seat angle connections.

\section{INTRODUCTION}

The three parameters power model was shown in Eq. (1) below:

$M=\frac{R_{\mathrm{ki}} \theta}{\left[1+\left(\theta / \theta_{0}\right)^{\mathrm{n}}\right]^{1 / \mathrm{n}}}$

where, $R_{\mathrm{ki}}$ is initial stiffness of the connections, $\theta_{0}=M_{\mathrm{u}} / R_{\mathrm{ki}}$ (a reference plastic rotation), $M_{\mathrm{u}}$ is ultimate moment capacity and $n$ is shape parameter.

\section{THE INITIA STIFFNESS (THE COMPONENT METHOD)}

When calculating initial stiffness, the members effecting initial stiffness were divided compressive region and tensile region according to different stress [1]. Tensile region: initial stiffness of tensile bolt $R_{\mathrm{t}, \mathrm{b}}$; initial stiffness of bending column flange $R_{\mathrm{t}, \mathrm{ff}}$; initial stiffness of tensile column web $R_{\mathrm{t}, \mathrm{cw}}$; initial stiffness of bending angle $R_{\mathrm{t}, \mathrm{a}}$. Compressive region: initial stiffness of compressive column web $R_{\mathrm{c}, \mathrm{cw}}$.

\subsection{The Initial Stiffness of Tensile Bolt}

According to Hooke's law, the displacement of single tensile bolt was shown in Eq. (2) and the initial stiffness was shown in Eq. (3):

$$
\begin{aligned}
\Delta_{\mathrm{b}, \mathrm{t}} & =\frac{F_{\mathrm{b}, \mathrm{t}} l_{\mathrm{b}}}{E A_{\mathrm{b}}} \\
R_{\mathrm{t}, \mathrm{b}} & =n_{\mathrm{b}} \frac{E A_{\mathrm{b}}}{l_{\mathrm{b}}}
\end{aligned}
$$

Where $\Delta_{\mathrm{b}, \mathrm{t}}$ is displacement of tensile bolt; $F_{\mathrm{b}, \mathrm{t}}$ is bolt tension; $A_{\mathrm{b}}$ is effective area of bolt; $l_{\mathrm{b}}$ is calculated length of bolt, $l_{\mathrm{b}}=t_{\mathrm{cf}}+t_{\mathrm{a}}, t_{\mathrm{a}}$ is angle thickness, $t_{\mathrm{cf}}$ is thickness of column flange; $R_{\mathrm{t}, \mathrm{b}}$ is tensile stiffness of bolt; $n_{\mathrm{b}}$ is numbers of tensile bolt closed to beam flange [2].

\subsection{The Initial Stiffness of Compressive Column Web}

The pressure on compressive flange of beam was transferred to column web by compressive angle, and pressure on column web was regarded as distributed load. The effective width $b_{\text {eff.cw }}$ of compressive column web was shown in Fig. (2) in previous work by [3] The displacement and the initial stiffness of compressive column web were shown in Eq. (4) and Eq. (5) below:

$\Delta_{\mathrm{cw}, \mathrm{c}}=\frac{F_{\mathrm{cw}, \mathrm{c}} h_{\mathrm{cw}}}{E b_{\mathrm{eff}, \mathrm{cw}} t_{\mathrm{cw}}}$
$R_{\mathrm{c}, \mathrm{cw}}=\frac{E b_{\mathrm{eff}, \mathrm{cw}} t_{\mathrm{cw}}}{h_{\mathrm{cw}}}$

where $\Delta_{\mathrm{cw}, \mathrm{c}}$ is displacement of compressive column web; $F_{\mathrm{cw}, \mathrm{c}}$ is pressure on column web; $h_{\mathrm{cw}}$ is height of column web; $b_{\text {eff,cw }}$ is effective compressive width of column web, $b_{\text {eff,cw }}=2 t_{\mathrm{a}}+r_{\mathrm{a}}+5\left(t_{\mathrm{cf}}+s\right) ; t_{\mathrm{cw}}$ is thickness of column web; $r_{\mathrm{a}}$ is arc radius at corner of angle toe, when column section is rolled, $s=r_{\mathrm{a}}$, when column section is welded, $s=h_{\mathrm{fc}}, h_{\mathrm{fc}}$ is weld leg size at junction between column flange and column web.

\subsection{The Initial Stiffness of Tensile Column Web}

The derivation process of initial stiffness of compressive column web were similar with tensile column web, except for difference of the effective width. The tensile effective width of column web was shown in previous work by [4], and the displacement and the initial stiffness of tensile column web were shown in Eq. (6) and Eq. (7) below:

$$
\begin{gathered}
\Delta_{\mathrm{cw}, \mathrm{t}}=\frac{F_{\mathrm{cw}, \mathrm{t}} h_{\mathrm{cw}}}{E b_{\mathrm{eff}, \mathrm{cw}}^{\prime} t_{\mathrm{cw}}} \\
R_{\mathrm{t}, \mathrm{cw}}=\frac{E b_{\mathrm{eff}, \mathrm{cw}}^{\prime} t_{\mathrm{cw}}}{h_{\mathrm{cw}}}
\end{gathered}
$$

where $\Delta_{\mathrm{cw}, \mathrm{t}}$ is displacement of tensile column web; $F_{\mathrm{cw}, \mathrm{t}}$ is pressure on column web; $b_{\text {eff,cw }}^{\prime}$ is effective tensile width of 
column web, $b_{\mathrm{eff}, \mathrm{cw}}^{\prime}=0.7 b_{\mathrm{eff}, \mathrm{cw}} ; R_{\mathrm{t}, \mathrm{cw}}$ is initial stiffness of column web.

\subsection{The Initial Stiffness of Bending Column Flange}

The pressure on tensile beam flange was transfer to column flange by bolt, and rotation disappeared at junctions between column web and column flange. So that bending column flange was regarded as $\mathrm{T}$ shape member, be shown in Fig. (1) below:

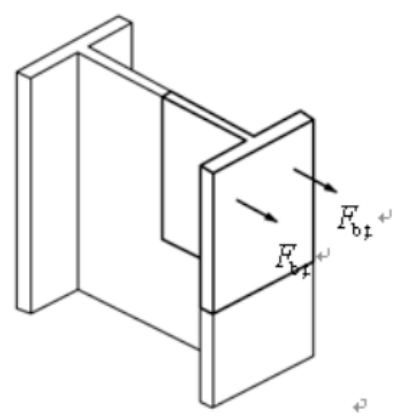

Fig. (1). The T shape member.

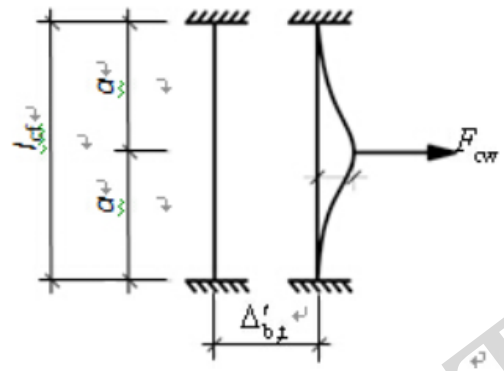

Fig. (2). Calculated model of bending column flange.

Considering pretension force of high strength bolt is very huge, first row bolts closed to column web were regarded as fixed end approximatively. The $\mathrm{T}$ shape member was regarded as beam fixed at both ends to calculate, the calculated model of T shape member was shown in Fig. (2) above [5].

The displacement at junction between column web and column flange was equivalent to displacement at midspan of beam under concentrated force at midspan of beam plus elongation of pretension bolt. The displacement is got by Eq. (8) and Eq. (9), and the initial stiffness is shown in Eq. (10).

$\Delta_{\mathrm{cf}, \mathrm{t}}=\frac{F_{\mathrm{cw}, \mathrm{t}} l_{\mathrm{cf}}^{3}}{192 E I_{\mathrm{cf}}}+\Delta_{\mathrm{b}, \mathrm{t}}^{\prime}$

$\Delta_{\mathrm{b}, \mathrm{t}}^{\prime}=\frac{F_{\mathrm{cw}, \mathrm{t}} t_{\mathrm{cf}}}{11 E A_{\mathrm{b}}}$

$R_{\mathrm{t}, \mathrm{cf}}=\frac{1}{\frac{l_{\mathrm{cf}}^{3}}{192 E I_{\mathrm{cf}}}+\frac{t_{\mathrm{cf}}}{11 E A_{\mathrm{b}}}}$

where $\Delta_{\mathrm{cf}, \mathrm{t}}$ is displacement at junction between column web and column flange under tension on column flange; $F_{\mathrm{cw}, \mathrm{t}}$ is tension on column web; $l_{\mathrm{cf}}$ is calculated length of tensile column flange, $l_{\mathrm{cf}}=2 a, a$ is distance of bolt closest to column web; $I_{\mathrm{cf}}$ is moment of inertia of column flange section, $I_{\mathrm{cf}}=b_{\text {eff }, \mathrm{t}} t_{\mathrm{cf}}^{3} / 12, b_{\text {eff,t }}$ is effective width of bending column flange, be shown in previous work by [4], $b_{\text {eff,t }}=2 \pi a ; \Delta_{\mathrm{b}, \mathrm{t}}^{\prime}$ is elongation of pretension bolt.

\subsection{The Initial Stiffness of Tensile Angle}

The calculated model of angle is shown in Fig. (3). Considering pretension of bolt is very huge, the situation at bolt is regarded as fixed end [6]. The angle displacement is shown in Fig. (4).

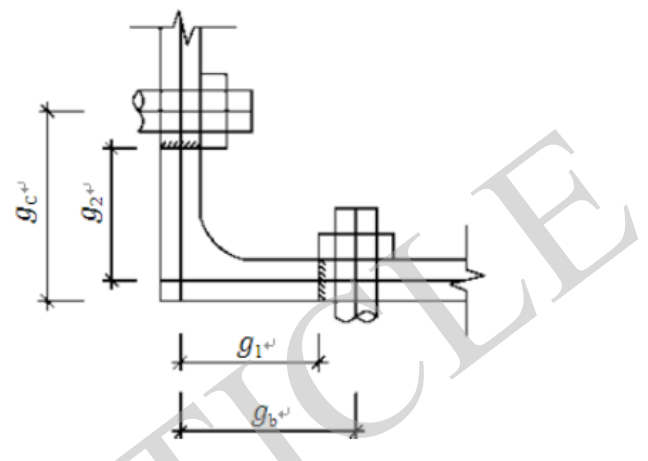

Fig. (3). Calculated model of angle.

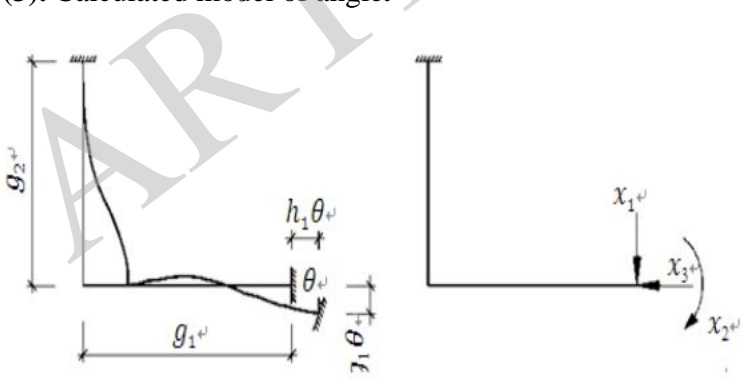

Fig. (4). Calculated drawing of angle.

Calculated drawing of angle is shown in Fig. (4), the member end force caused by member end displacement is gotten by principle of virtual work, $\left\{x_{1}, x_{2}, x_{3}\right\}^{\mathrm{T}}$. Due to similar between length of angle toe and thickness of angle toe, shearing deformation should be considered [7]. The derivation process are shown in Eq. (11) Eq. (14) below:

$$
\begin{aligned}
& \left\{x_{1}, x_{2}, x_{3}\right\}^{\mathrm{T}}=\left\{\alpha, \alpha \beta, \frac{1}{3} g_{1} \alpha\right\}^{\mathrm{T}} \\
& \alpha=\frac{3 E I_{\mathrm{a}} h_{1} \theta}{\beta g_{2}^{3}-g_{1} g_{2}^{2}}
\end{aligned}
$$

$\beta$

$$
\begin{aligned}
& =\frac{1}{g_{2}^{2}}\left(\frac{4}{3} g_{1} g_{2}+\frac{1}{3} g_{1}^{2}\right) \\
& R_{\mathrm{t}, \mathrm{a}}=M / \theta=\frac{3 E I_{\mathrm{a}} \beta g_{1} h_{1}}{\beta g_{1} g_{2}^{3}-g_{1}^{2} g_{2}^{2}}
\end{aligned}
$$

where $I_{\mathrm{a}}$ is moment of inertia of angle; $g_{2}$ is calculated length of junction between top angle and beam flange, $g_{1}=g_{\mathrm{b}}-D / 2-t_{\mathrm{a}} / 2, g_{\mathrm{b}}$ is distance from junction between top angle and column flange to first row bolt hole center of beam, $D$ is diameter of bolted cap; $g_{2}=g_{\mathrm{c}}-D / 2-t_{\mathrm{a}} / 2, g_{\mathrm{c}}$ is distance from junction between top angle and column flange to first row bolt hole center of column; $h_{1}$ is distance between top angle and seat angle, $h_{1}=h_{\mathrm{b}}+t_{\mathrm{a}}, h_{\mathrm{b}}$ is height of beam. 


\subsection{The Initial Stiffness of Semirigid Connection}

Due to above-mentioned four tensile region are linked with series pattern, the initial stiffness of tensile region is shown in Eq. (15) below:

$\frac{1}{R_{\mathrm{t}}}=\frac{1}{R_{\mathrm{t}, \mathrm{b}}}+\frac{1}{R_{\mathrm{t}, \mathrm{cf}}}+\frac{1}{R_{\mathrm{t}, \mathrm{cw}}}+\frac{1}{R_{\mathrm{t}, \mathrm{a}}}$

where $R_{\mathrm{t}}$ is initial stiffness of tensile region.

The angle rotation caused by connection moving included rotation of compressive region and rotation of tensile region. The derivation process are shown in Eq. (16) Eq. (18) below:

$R_{\mathrm{ki}}=\frac{M}{\theta}$

$\theta=\frac{\Delta_{\mathrm{t}}+\Delta_{\mathrm{c}, \mathrm{cw}}}{h_{1}}$

$M=F_{\mathrm{bf}, \mathrm{t}} \times h_{1}$

where $\theta$ is total angular rotation; $\Delta_{\mathrm{t}}$ is linear displacement in tensile region, $\Delta_{\mathrm{t}}=F_{\mathrm{bf}, \mathrm{t}} / R_{\mathrm{t}}, F_{\mathrm{bf}, \mathrm{t}}$ is tension on beam flange; $\Delta_{\mathrm{c}, \mathrm{cw}}$ is linear displacement in compressive region, $\Delta_{\mathrm{c}, \mathrm{cw}}=F_{\mathrm{bf}, \mathrm{c}} / R_{\mathrm{c}, \mathrm{cw}}, F_{\mathrm{bf}, \mathrm{c}}$ is pressure on beam flange; $M$ is moment of beam.
The Eq. (16) and Eq. (17) are substituted into The Eq. (18), and the result is shown in Eq. (19) below.

$R_{\mathrm{ki}}=\frac{h_{1}^{2}}{\frac{1}{R_{\mathrm{t}}}+\frac{1}{R_{\mathrm{c}, \mathrm{cw}}}}$

\section{THE EXAMPLE ANALYSIS AND FORMULA FIT- TING}

The dimensions of connections was shown in Table $\mathbf{1}$ below.

The results of initial stiffness by Eq. (19) were shown in Table 2. The major effective factor of initial stiffness is angle tensile initial stiffness $\left(R_{\mathrm{t}, \mathrm{a}}\right)$ from Table 2 , and the fitted formula is shown in Eq. (20) considering other effective factor of initial stiffness.

$R_{\mathrm{ki}}=\frac{0.19 E b_{\mathrm{b}} t_{\mathrm{a}}^{3} h_{\mathrm{b}}^{2} t_{\mathrm{cw}}\left(8 t_{\mathrm{a}}+5 t_{\mathrm{cf}}\right)}{1.1 b_{\mathrm{b}} t_{\mathrm{a}}^{3} h_{\mathrm{cw}}+4.1 d_{\mathrm{e}}^{3}\left(8 t_{\mathrm{a}}+5 t_{\mathrm{cf}}\right) t_{\mathrm{cw}}}$

where $E$ is elastic modulus of steel; $b_{\mathrm{b}}, h_{\mathrm{b}}$ are width of beam and height of beam respectively; $t_{\mathrm{a}}$ is thickness of angle; $h_{\mathrm{cw}}, t_{\mathrm{cf}}, t_{\mathrm{cw}}$ are height of column web, thickness of column flange and height of column web respectively. $d_{\mathrm{e}}$ is effective diameter of bolt.

Table 1. Dimension of connection models.

\begin{tabular}{|c|c|c|c|c|}
\hline No. & Column Section (mm) & Beam Section (mm) & Angle Section (mm) & BoltDiameter (mm) \\
\hline \hline 1 & HW200X200X8X12 & HW150X150X7X10 & 2L100X80X8 & 16 \\
\hline 2 & HW250X250X9X14 & HW200X200X8X12 & 2L100X80X10 & 16 \\
\hline 3 & HW300X300X10X15 & HW250X250X9X14 & 2L140X90X12 & 16 \\
\hline 4 & HW350X350X12X19 & HW300X300X10X15 & 2L140X90X14 & 22 \\
\hline
\end{tabular}

Table 2. Initial stiffness of connection (Calculaed by Eq. (19)).

\begin{tabular}{|c|c|c|c|c|c|c|c|}
\hline $\mathbf{N o}$ & $\mathbf{R}_{\mathrm{t}, \mathrm{b}}(\mathbf{N} \cdot \mathbf{m} / \mathbf{r a d})$ & $\mathbf{R}_{\mathrm{c}, \mathrm{ww}}(\mathbf{k N} \cdot \mathbf{m} / \mathbf{r a d})$ & $\mathbf{R}_{\mathrm{t}, \mathrm{w}}(\mathbf{k N} \cdot \mathbf{m} / \mathbf{r a d})$ & $\left.\mathbf{R}_{\mathrm{t}, \mathrm{cf}} \mathbf{k N} \cdot \mathbf{m} / \mathbf{r a d}\right)$ & $\mathbf{R}_{\mathrm{t}, \mathrm{a}}(\mathbf{k N} \cdot \mathbf{m} / \mathbf{r a d}$ & $R_{\mathbf{t}}(\mathbf{k N} \cdot \mathbf{m} / \mathbf{r a d})$ & $\left.R_{\mathrm{ki}} \mathbf{k N} \cdot \mathbf{m} / \mathbf{r a d}\right)$ \\
\hline \hline 1 & 4140 & 1273 & 891 & 1644 & 115 & 94 \\
\hline 2 & 3450 & 1253 & 877 & 1184 & 427 & 217 \\
\hline 3 & 6133 & 1305 & 913 & 1099 & 247 & 161 & 11369 \\
\hline 4 & 4743 & 1545 & 1082 & 1569 & 564 & 282 \\
\hline
\end{tabular}

Table 3. Initial stiffness of connection (fitted value).

\begin{tabular}{|c|c|c|c|c|c|c|c|c|c|c|}
\hline No. & $\begin{array}{c}\boldsymbol{E} \\
\left(\mathbf{N} / \mathbf{m m}^{2}\right)\end{array}$ & $\begin{array}{c}\boldsymbol{b}_{\mathrm{b}} \\
(\mathbf{m m})\end{array}$ & $\begin{array}{c}\boldsymbol{h}_{\mathrm{b}} \\
(\mathbf{m m})\end{array}$ & $\begin{array}{c}\boldsymbol{t}_{\mathrm{a}} \\
(\mathbf{m m})\end{array}$ & $\begin{array}{c}\boldsymbol{t}_{\mathrm{cf}} \\
(\mathbf{m m})\end{array}$ & $\begin{array}{c}\boldsymbol{t}_{\mathbf{c w}} \\
(\mathbf{m m})\end{array}$ & $\begin{array}{c}\boldsymbol{h}_{\mathrm{cw}} \\
(\mathbf{m m})\end{array}$ & $\begin{array}{c}\boldsymbol{d}_{\mathrm{e}} \\
(\mathbf{m m})\end{array}$ & $\begin{array}{c}\boldsymbol{R}_{\mathbf{k i}} \\
(\mathbf{k N} \cdot \mathbf{m} / \mathbf{r a d})\end{array}$ & $\begin{array}{c}\text { Fitted value/ } \\
\mathbf{E q} \cdot(\mathbf{1 9})\end{array}$ \\
\hline \hline 1 & 206000 & 150 & 150 & 8 & 12 & 8 & 176 & 16 & 2165 \\
\hline 2 & 206000 & 200 & 200 & 10 & 14 & 9 & 222 & 16 & 6015 & 1.04 \\
\hline 3 & 206000 & 250 & 250 & 12 & 15 & 10 & 270 & 16 & 11711 & 1.02 \\
\hline 4 & 206000 & 300 & 300 & 14 & 19 & 12 & 312 & 22 & 18747 & 1.00 \\
\hline
\end{tabular}


The initial stiffness in Table $\mathbf{1}$ are calculated with Eq. (20) again and the results are analyzed comparatively with initial stiffness in Table $\mathbf{2}$. The Table $\mathbf{3}$ show us every parameter value, results and ratio of fitted value and Eq. (20). The Eq. (20) is more convenient than Eq. (19) from Table $\mathbf{3}$, and the error is in the allowed range in practical design [8].

\section{CONCLUSION}

In this paper, according to stress characteristic and failure mode of top and seat angle semirigid connections, the component method are used to derivate initial stiffness and get analysis formula and fitted formula. Those results were analyzed with test data and verify correction of formulas. The results provide good theoretical foundation for practical design method of project.

\section{CONFLICT OF INTEREST}

The authors confirm that this article content has no conflict of interest.

\section{ACKNOWLEDGEMENTS}

This work was supported by the Natural Science Foundation of the Anhui Education Institution of China (Grant No. KJ2014A217) and the Discipline Leaders of Hefei Universi- ty of China (Grant No. 2014dtr01) and the Construction of Key Subject of Hefei University of China (Grant No. 2014xk04).

\section{REFERENCES}

[1] N. Kishi and W. F. Chen, "Moment-rotation relation of semi-rigid connections with angles,' Journal of Structural Engineering, vol. 116, no. 7, pp. 1813-34, 1990.

[2] W.F Chen, and N. Kishi, "Semi-rigid steel beam-to-column connections: data and modeling," Journal of Structural Engineering, vol. 115, no. 1. pp. 105-119, 1989.

[3] R. A. Heehtman, and B.G. Johnston, "Riveted semi-rigid beam-tocolumn building connection," Journal of Constructional Steel Research, vol. 5, no. 3, pp. 86-96, 1982.

[4] J.A. Paeker, and L. J. A. Morris, "Limited state design method of the tension region of bolted beam-column connections,' The Structural Engineering, vol. 10, no. 5, pp. 446-458, 1997.

[5] D.C. Drucker, "The effect of shear on the plastic bending of beams," Journal of Applied Mecchanics, ASME, vol. 23, no. 4, pp. 509-514, 2001.

[6] A. Ali, "Nonlinear analysis on prying of top-seat angle connections, Journal of Applied Mechanics, JSCE, vol. 4, no. 1, pp. 227236, 2001.

[7] S. M. Maxwell, A Realistic Approach to The Performance and Application of Semi-rigid Joints in Steel Structures, Joints in Structural Steel work, Pentech Press, USA, 1981.

[8] N. Kishi and W.F. Chen, Data Base of Steel Beam-Column Connection, Structural Engineering, CE-STR-86-26, vol. 1, no. 2, Purdue University, 1986.

\footnotetext{
Received: January 25, 2015

(C) Wei and Ganping; Licensee Bentham Open.

This is an open access article licensed under the terms of the Creative Commons Attribution Non-Commercial License (http://creativecommons.org/-
} licenses/by-nc/3.0/) which permits unrestricted, non-commercial use, distribution and reproduction in any medium, provided the work is properly cited. 